\title{
Orthography plays a critical role in cognate priming: Evidence from French/English and Arabic/French cognates
}

\author{
JEFFREY S. BOWERS \\ University of Bristol, Bristol, England \\ ZOHRA MIMOUNI \\ Institut Universitaire de Gériatrie de Montréal, Montreal, Quebec, Canada \\ and \\ MARTIN ARGUIN \\ Université de Montréal, Montreal, Quebec, Canada \\ and Institut Universitaire de Gériatrie de Montréal, Montreal, Quebec, Canada
}

\begin{abstract}
A series of three experiments was carried out in order to better characterize the representations that support long-term cognate priming. In Experiment 1, robust priming was obtained between orthographically similar French/English cognates in bilingual speakers, and this priming was mediated, in part, by orthographic codes, given that priming for these items was dramatically reduced following a study-test modality shift. In Experiment 2, no priming was obtained between the same set of French/English cognates in monolingual English speakers. Finally, in Experiment 3, priming for orthographically unrelated Arabic/French cognates was no larger than cross-modal priming, suggesting that these effects were mediated by nonorthographic representations. The role of orthography in supporting cognate priming is discussed.
\end{abstract}

Long-term priming refers to a facilitation in processing a stimulus as a consequence of having encountered the same (or a related) stimulus in an earlier episode. Generally, this facilitation is measured in terms of an improved accuracy or a reduced latency in identifying studied materials, as compared with nonstudied materials. In the lexical decision task, for example, participants decide as quickly as possible whether letter strings spell words, and priming is obtained when they respond more accurately or quickly to repeated words. This form of priming is called long term because it lasts minutes, hours, or longer (Sloman, Hayman, Ohta, Law, \& Tulving, 1988), in contrast to various sorts of short-term priming phenomenasuch as semantic (e.g., Henderson, Wallis, \& Knight, 1984) or masked (Forster \& Davis, 1984) priming - that typically last only a few seconds (but see Joordens \& Becker, 1997).

Long-term priming-what we simply refer to as priming in the remainder of the article-has been extensively studied during the past 15 years (for reviews, see Bowers, 2000; Roediger \& McDermott, 1993; Tenpenny, 1995). One key finding consistently reported in the liter-

We thank Judith Kroll, Marilyn Smith, and an anonymous reviewer for helpful comments on previous versions of this article. Correspondence concerning this article should be addressed to J. S. Bowers, Department of Experimental Psychology, 8 Woodland Rd., Bristol B58 1TN, England (e-mail: j.bowers@bris.ac.uk). ature is that priming is sensitive to various study-to-test changes in the perceptual format of items. For example, priming tends to be reduced by $50 \%$ or more when items are studied and tested in a different modality, rather than in the same modality (e.g., Jacoby \& Dallas, 1981). Similarly, priming is dramatically reduced when items are presented in pictorial and written formats at study and test, or vice versa (e.g., Rajaram \& Roediger, 1993), or when words are form related (e.g., the prime table does not prime cable; e.g., Napps \& Fowler, 1987). In addition, little or no cross-language priming is obtained in bilingual speakers. For example, the word dog does not prime the word chien in an English/French speaker, despite the fact that the words refer to the same concept (see, e.g., Kirsner, Smith, Lockhart, King, \& Jain, 1984). These and related findings have led to the view that priming is mediated by perceptual as opposed to conceptual representations, at least when priming is assessed in tests that emphasize the perceptual encoding of the targets-so-called data-driven tests (Blaxton, 1989).

Exceptions to this general rule have been found, however. For example, robust priming is obtained between upper- and lowercase English words that share few perceptual features (Bowers, 1996) and between visually unrelated scripts of a language, such as the Kanji/Hiragana scripts of Japanese (Bowers \& Michita, 1998), the Hindi/ Urdu scripts of Hindustani used in Northern India (Brown, Sharma, \& Kirsner, 1984), and the Roman/Cyrillic scripts of Serbo-Croatian (Feldman \& Moskovljevic, 1987). In 
addition, robust priming is obtained between morphologically related words (e.g., cars/car), and these effects cannot be attributed to the perceptual overlap between items, given that little or no priming is obtained between nonmorphologically related words that share the same degree of perceptual overlap, such as card/car (see, e.g., Bowers, Damian, \& Havelka, 1999; Napps \& Fowler, 1987). Finally, and in contrast with the general finding that priming is language specific, robust priming is obtained between translation equivalents that are phonologically related, such as the French/English words carte/ card-that is, when the study/test words are cognates (see, e.g., Cristoffanini, Kirsner, \& Milech, 1986). These results show that, under some circumstances, priming is robust following study-to-test changes in the perceptual format of items.

On the basis of a combination of modality-specific and perceptually abstract priming, a number of authors have argued that visual word priming is mediated by preexisting lexical-orthographic codes (e.g., Bowers, 1999, 2000; Bowers \& Michita, 1998; Morton, 1979). On this general view, a by-product of reading a word is that its orthographic representation is strengthened; this in turn facilitates its subsequent identification. Importantly, this view can readily account for the above-mentioned findings because orthographic representations are abstract in many of the ways that priming is abstract, including the fact that visually dissimilar upper- and lowercase letters and words map onto common orthographic representations (e.g., A/a; see, e.g., Bowers, Vigliocco, \& Haan, 1998; Coltheart, 1981), as do morphological relatives (Rapp, 1992).

Apart from providing a general theory of word priming, this framework suggests that long-term priming can be used as a tool to study the structure of orthographic knowledge-and perceptual knowledge in general. Indeed, priming has been used to study the structure of perceptual codes used for object identification (e.g., Biederman \& Gerhardstein, 1993; Marsolek, Kosslyn, \& Squire, 1992; Srinivas, 1995), spoken word recognition (e.g., Church \& Schacter, 1994; Goldinger, 1996), and visual word identification (Bowers \& Michita, 1998; Morton, 1979). In the present investigation, we focus on the above-mentioned cognate priming results. The dual aim of the investigation is to better characterize the conditions in which cognate priming occurs, as well as to gain some preliminary insight into how (or whether) cognate relations are coded within the orthographic system.

The hypothesis that cognate relations are explicitly coded within the orthographic system is made plausible by recent findings suggesting that written words in different languages are processed within a common orthographic system (e.g., Grainger \& Dijkstra, 1992; for reviews of this issue, see Kroll \& deGroot, 1997; Smith, 1997). For example, van Heuven, Dijkstra, and Grainger (1998) found that lexical decisions to English words are affected by their orthographic overlap with Dutch words in bilingual Dutch/English speakers, with slower response times (RTs) to English words similar to many Dutch words (i.e., English words in high-density Dutch neighborhoods) than to English words dissimilar to most Dutch words (English words in low-density Dutch neighborhoods). These findings, among others, strongly suggest that access to the orthographic system is language nonspecific, and indeed, Dijkstra and colleagues (e.g., Dijkstra \& van Heuven, 1998; Grainger \& Dijkstra, 1992) have successfully simulated these and related findings in a computational model of orthographic processing in which words in different languages are processed within a common system (but see Kirsner et al., 1984; Scarborough, Gerard, \& Cortese, 1984).

Although the orthographic system appears to be language nonspecific, relatively little work has investigated whether cognate relations are explicitly coded within this system, either in term of common abstract representations or through strongly interconnected representations. There is some evidence that orthographically identical cognates (e.g., general in Spanish and English) map onto common codes (see, e.g., Caramazza \& Brones, 1979), but these findings do not speak to the issue of whether the relations between heterographic cognates (e.g., cremal cream in Spanish and English) are explicitly coded.

Perhaps the most relevant evidence has been obtained in studies employing the masked-priming paradigm. In this paradigm, the prime and the target are presented in immediate succession, and priming is measured as a facilitation in processing the target when it is related to, as compared with unrelated to, the prime. This facilitation occurs even though the prime is briefly presented (a typical prime duration is $50 \mathrm{msec}$ ) and a premask acts to block perception of the prime. In the critical studies, participants made lexical decisions to the targets, and robust priming was obtained between orthographically similar cognates (e.g., cream/crema; de Groot \& Nass, 1991; Sanchez-Casas, Davis, \& Garcia-Albea, 1992). However, noncognate translation equivalents typically show much less (or no) priming in the bilingual speakers (de Groot \& Nass, 1991; Sanchez-Casas et al., 1992), and monolinguals presented with cognates fail to show any priming (Garcia-Albea, Sanchez-Casas, Bradley, \& Forster, 1985). These latter results suggest that cognate priming in bilinguals cannot be attributed to the semantic or perceptual overlap between items, providing some support for the hypothesis that cognate relations are explicitly coded within the orthographic system. In a more recent study, Gollan, Forster, and Frost (1997) assessed masked priming effects between Hebrew/English cognates that are phonologically similar but orthographically unrelated. Once again, the authors found cognate priming, but the pattern of results was somewhat complex, given that robust priming was also obtained between noncognate translation equivalents under some conditions (in some cases, this priming was as large as the cognate results). On the basis of these results, it appears that prim- 
ing in the masked-priming paradigm can be attributed to semantic or conceptual representations under some circumstances.

In addition, a few studies have employed the long-term priming paradigm to address this issue. The first study was reported by Cristoffanini et al. (1986), who obtained priming between Spanish/English cognates in a lexical decision task. In the study phase, participants named aloud Spanish and English words presented in blocks, and at test they made lexical decisions to English words. Interestingly, a similar amount of cognate priming was obtained between items that are orthographically identical (e.g., festival/festival) and orthographically similar (e.g., observacion/observation). Averaging across a number of conditions, the cognate priming was .85 the size of within-language repetition priming. Furthermore, the authors failed to obtain priming between noncognate translation equivalents (e.g., panaderia/bakery), indicating that the cognate effects cannot be attributed to the common conceptual representations that cognates share. Similarly, Monsell, Matthews, and Miller (1992) observed cognate priming in the picture-naming task. In the study phase, participants generated Welsh or English words from definitions and, at test, named pictures in Welsh. Robust priming was obtained for words repeated in the same language $(92 \mathrm{msec})$ and for cognates $(63 \mathrm{msec})$, but once again, no priming was obtained for the noncognate translation equivalents $(-7 \mathrm{msec})$.

What is the basis of these long-term effects? As in the case of the masked-priming results, it is difficult to attribute the long-term cognate priming to a simple additive combination of orthographic, phonological, and semantic factors, given that no long-term priming is obtained between translation equivalents that are noncognates (e.g., Kirsner et al., 1984; but see the General Discussion section for one exception), that little or no priming is obtained between orthographically related words presented once at study and once at test (e.g., Bowers et al., 1999; Napps \& Fowler, 1987; see Rueckl, 1990, for evidence that multiple encounters with orthographically related words produce small priming effects), and that priming between homophones is very much reduced, in comparison with repetition (ànd cognate) priming (Neisser, 1954; Rueckl \& Mathew, 1999; Ziemer \& Bowers, 1999).

This leaves at least two alternatives. On the one hand, some combination of orthographic, phonological, and semantic codes may interact in a superadditive fashion in order to mediate these effects. In this way, cognate priming might occur even if there was no explicit coding of cognate relations within the orthographic system or elsewhere (e.g., Rueckl \& Olds, 1993; Tenpenny, 1995). It should be noted, however, that a recent finding by Dijkstra, Grainger, and van Heuven (1999) appears to pose a challenge for this view. The authors found that Dutch/ English bilinguals are slower in making lexical decisions to English words phonologically related to Dutch words (although semantic and orthographic overlap between words in the two languages led to faster RTs). That is, phonological overlap between Dutch/English words appeared to impair the processing of English words, owing to some sort of competitive process, which would work against the hypothesis that the phonological overlap between cognates contributes to cognate priming.

A second possibility is that long-term cognate priming depends on an explicit coding of cognate relations within the orthographic system, so that studying one member of a cognate pair strengthens the representation of the other member. This account is very much like the standard interpretation of morphological or cross-script priming (Bowers, 2000).

The studies described below further explore long-term cognate priming phenomena in an attempt to shed some light on these issues. In Experiment 1, priming between French/English cognates was assessed in bilingual subjects, and cognate effects were compared with repetition and cross-modal priming in order to determine whether cognate priming should be attributed to modality-specific or modality-nonspecific representations. If modalityspecific cognate priming is obtained, it would lend support to the view that orthographic representations contribute to the priming independently from phonological or semantic factors. In Experiment 2, priming for the same set of words was assessed in monolingual English participants in order to determine the contribution of perceptual overlap in supporting any cognate results obtained in Experiment 1. Finally, in Experiments $3 \mathrm{~A}$ and 3B, cognate priming was assessed between orthographically unrelated French/Arabic and Arabic/French cognates in bilingual participants, and these effects were again compared with repetition and cross-modal priming. A comparison of the cognate priming results in Experiments 1, $3 \mathrm{~A}$, and $3 \mathrm{~B}$ will determine whether orthographic overlap is a necessary condition in order to obtain any modalityspecific or modality-nonspecific cognate priming.

\section{EXPERIMENT 1}

The first experiment assessed priming between French/ English cognates in bilingual speakers. In past studies, robust priming was obtained between orthographically similar items. The critical question here is whether this priming should be attributed to modality-specific or modality-nonspecific representations.

\section{Method}

Participants. Twenty French/English bilingual students from the University of Montreal participated in the experiment. The first language of all the participants was French, but they were all fluent in English and used it on a daily basis.

Design and Materials. The experiment included study-test relation as a within-subjects variable with four levels: Study and test words were visually repeated in French (repeated condition) versus visually studied in English and tested in French (cognate condition) versus auditorily studied in French and visually tested in French (cross-modal condition) versus nonstudied and visually tested in 
French (baseline condition). Four test forms were created so that each word would be included in the four conditions equally often, yielding a completely counterbalanced design. An equal number of participants was tested on each form.

A set of 60 orthographically similar (but nonidentical) French/ English cognates was selected for the experiment. The French words had a mean frequency of 75 and a range of 14-383 occurrences per million (Baudot, 1992), and the English words had a mean frequency of 68 and a range of 1-298 occurrences per million (Kučera $\&$ Francis, 1967). The participants studied 45 critical words ( 15 in each of the repeated, cognate, and cross-modal conditions) presented in a random order so that items in the different conditions were intermixed. At test, all 60 items were presented, so the 15 nonstudied words served as baseline items in order to compute priming values. In addition to the 60 words presented at test, a set of 60 phonologically plausible French nonwords was constructed to match the words in overall length and were used in the lexical decision task. Test items were again presented in a random order. Finally, a set of 10 filler French words and 10 filler nonwords was included as the first 20 trials in the lexical decision task. These trials were included to give the participants some practice in making lexical decisions before they completed the critical trials. The filler items were different from the critical items.

The words in the lexical decision task were presented in the speakers' primary language--in this case, French. We decided to test the speakers in the primary language so that we could more directly compare the present results with those of Experiment 2, in which monolinguals were tested in their primary (only) language. The first experiment was conducted on a PowerBook 170 computer with an active matrix screen, using the Psychlab software package (Bub \& Gum, 1988).

Procedure. This and the following experiments were conducted under conditions of incidental encoding: The participants were not informed that many of the words in the lexical decision task had been previously presented in the study phase of the experiment.

In the study phase, the words were presented one at a time every $5 \mathrm{sec}$, and the participants were asked to read aloud the visually presented items and to repeat aloud the spoken words. Immediately after completing the study phase, the participants performed the lexical decision task by pressing the right shift key as quickly as possible whenever a word was displayed and the left shift key as quickly as possible otherwise.

\section{Results and Discussion}

In all the experiments, analyses of variance (ANOVAs) were carried out, treating participants as a random factor, and an alpha level of .05 was used. The mean lexical decision latencies for correct responses and error rates in Experiment 1 in the various conditions are shown in Table 1. An overall ANOVA carried out on the RT data revealed a main effect of study-test relation $[F(3,48)=$ $7.64, M S_{\mathrm{e}}=4831$, reflecting robust repetition $(28 \mathrm{msec})$ and cognate $(27 \mathrm{msec})$ priming. Note that the equivalent amount of priming obtained for cognates and repeated items is consistent with past results (e.g., Cristoffanini et al., 1986). The critical new finding is that cognate priming was significantly greater than cross-modal priming $\left[13 \mathrm{msec} ; F(1,48)=4.44, M S_{\mathrm{e}}=483\right]$, indicating that cognate priming was mediated, in large part, by modalityspecific visual codes. Cross-modal priming only approached significance $\left[F(1,48)=3.50, M S_{\mathrm{e}}=483, p=\right.$ $.07]$. An analysis carried out on the error scores failed to reveal any significant effects $[F(3,48)<1]$. These findings are consistent with the hypothesis that cognate relations are explicitly coded within the orthographic system.

\section{EXPERIMENT 2}

In Experiment 2, a group of monolingual English participants was tested with the same set of cognate pairs as above. For these speakers, the words do not function as cognates, and accordingly, any priming between items can be attributed to the perceptual overlap between items.

\section{Method}

Participants. Twenty monolingual English students from the University of Houston participated in the experiment. Many of the participants studied Spanish in high school, but they all reported that they were not fluent in Spanish and that they rarely heard or used Spanish in everyday life. None of the participants had any knowledge of French.

Design and Materials. As in Experiment 1, the experiment included study-test relation as a within-subjects variable with four levels: repeated versus cognate versus cross-modal versus baseline. In contrast with Experiment 1, the test words were in English (as were the study words in the repeated and cross-modal conditions). Four test forms were created so that each word would be included in the four conditions equally often, yielding a completely counterbalanced design.

The same set of 60 cognates as that used in Experiment 1 was used in the present experiment. In addition, 60 phonologically plausible nonwords constructed to match the English words in overall length were used in the lexical decision task. As in Experiment 1, the critical study and test items were presented in a random order. Finally, a set of 10 filler English words and 10 filler nonwords was included as the first 20 trials in the lexical decision task. These trials were included to give the participants some practice in making lexical de-

Table 1

Lexical Decision Latencies (RTs, in Milliseconds), Error Rates, and Priming Values

for French/English Cognates in Bilingual and Monolingual Speakers as a Function of the Study-Test Condition in Experiments 1-2

\begin{tabular}{|c|c|c|c|c|c|c|c|c|}
\hline \multirow[b]{3}{*}{ Priming } & \multicolumn{8}{|c|}{ Speakers } \\
\hline & \multicolumn{4}{|c|}{$\begin{array}{l}\text { French/English Bilinguals } \\
\text { (Test Language French) }\end{array}$} & \multicolumn{4}{|c|}{$\begin{array}{l}\text { English Monolinguals } \\
\text { (Test Language English) }\end{array}$} \\
\hline & $\mathrm{RT}$ & $\begin{array}{l}\text { RT Priming } \\
\text { Value }\end{array}$ & $\% \mathrm{E}$ & $\begin{array}{c}\text { \% E Priming } \\
\text { Value }\end{array}$ & $\mathrm{RT}$ & $\begin{array}{l}\text { RT Priming } \\
\text { Value }\end{array}$ & $\% \mathrm{E}$ & $\begin{array}{l}\text { \% E Priming } \\
\text { Value }\end{array}$ \\
\hline Repeat & 536 & 28 & 8.3 & 2.9 & 594 & 19 & 2.3 & 0.01 \\
\hline Cognate & 537 & 27 & 12.1 & -0.9 & 623 & -10 & 4.7 & -2.3 \\
\hline Cross-modal & $55 !$ & 13 & 9.9 & 1.3 & 614 & -1 & 3.7 & -1.3 \\
\hline Baseline & 564 & & 11.2 & & 613 & & & 2.4 \\
\hline
\end{tabular}


cisions before they completed the critical trials. Filler items were different from the critical items. A laptop PC notebook with an active matrix screen was used to test the participants, and the experiment was run using the DMASTER software developed by K. I. Forster and J. C. Forster at the University of Arizona.

Procedure. The procedure was similar to that of Experiment 1 , except that during the study phase, the students were told that some of the written words were nonwords (in actuality, these were the French words) and they were simply asked to pronounce the items as best they could.

\section{Results and Discussion}

The mean lexical decision latencies for correct responses and error rates in the various conditions are shown in Table 1. As can be seen in this table, overall priming was reduced in comparison with Experiment 1, with approximately $10 \mathrm{msec}$ less repetition and crossmodal priming. The reason for this reduction is unclear. What is critical for present purposes, however, is that the robust cognate priming observed in Experiment 1 was eliminated here. An ANOVA carried out on the RT data revealed a main effect of study-test relation $[F(3,48)=$ $\left.2.84, M S_{\mathrm{e}}=1,067\right]$, reflecting the significantly larger repetition $(19 \mathrm{msec})$ priming, as compared with cognate $(-10 \mathrm{msec})$ and cross-modal $(-1 \mathrm{msec})$ priming. In contrast with Experiment 1, repetition priming was significantly greater than cognate priming $[F(1,16)=6.02$, $\left.M S_{\mathrm{e}}=1,410\right]$. The analysis of the error scores failed to reveal a significant effect $\left[F(3,48)=1.72, M S_{\mathrm{e}}=14.97\right]$ The failure to obtain cognate priming in monolingual speakers shows that the cognate priming obtained with bilingual speakers in Experiment 1 was not due to the visual overlap between items.

\section{EXPERIMENTS 3A AND 3B}

Given that the modality-specific cognate priming obtained in Experiment 1 cannot be attributed to the perceptual overlap between items, it appears that cognate relations are indeed explicitly coded within the orthographic system, much as is the case for upper- and lowercase English words (Bowers, 1996) and Hiragana/Katakana scripts in Japanese (Bowers \& Michita, 1998). However, it is still possible that orthographic overlap is a necessary precondition in order to obtain cognate effects, unlike the Japanese cross-script priming. In order to test this possibility, priming was assessed between cognates that are phonologically but not orthographically related, as in the Gollan et al. (1997) study. In this case, however, priming was assessed between Arabic and French cognates. Priming was assessed in both directions-that is, from French to Arabic (Experiment 3A) and from Arabic to French (Experiment 3B). As in the earlier experiments, these effects were contrasted with those of repetition and cross-modal priming.

\section{Method}

Participants. Thirty-two Arabic/French bilingual speakers of Middle Eastern origin who lived in Montreal participated in the experiment. All the participants came from Lebanon, apart from one person from Tunisia, and their native language was Arabic. All the participants started learning French in the second or third year of primary school, and in secondary school most of the scientific subjects (biology, math, physics, chemistry, etc.) were taught in French. All the students completed primary and secondary school in the Middle East and came to the University of Montreal (a Frenchspeaking university) for further studies. The average of years of French for all the participants was 16 years (they were between 19 and 25 years old), and they all considered themselves fluent in both Arabic and French. Sixteen of the participants performed lexical decisions in Arabic at test, and 16 performed lexical decisions in French at test.

Design and Materials. The experiments included study-test relation as a within-subjects variable with the same four levels: repeated versus cognate versus cross-modal versus baseline. In Experiment $3 \mathrm{~A}$, the test words were presented in Arabic (as were the study words in the repeated and cross-modal conditions), and in Experiment $3 \mathrm{~B}$, the test words were presented in French (as were the study words in the repeated and cross-modal conditions). Four test forms were created for each experiment so that each word would be included in the four conditions equally often, yielding completely counterbalanced designs.

The same set of 60 familiar Arabic/French cognates was used in Experiments $3 \mathrm{~A}$ and $3 \mathrm{~B}$. As in the earlier studies, 45 words were studied ( 30 visually, 15 auditorily), and all 60 items were tested. In addition, 60 Arabic and 60 French pronounceable nonwords were constructed for the lexical decision task in Experiments $3 \mathrm{~A}$ and $3 \mathrm{~B}$, respectively. The nonwords were constructed to be similar in overall complexity to the words. These study and test items were again presented in a random order. Finally, a set of 10 filler Arabic words and 10 filler nonwords was included as the first 20 trials in the lexical decision task in Experiment $3 \mathrm{~A}$, and corresponding French words and nonwords were included in Experiment $3 \mathrm{~B}$. All the filler items were different from the critical items.

We attempted to match the phonological overlap between these Arabic/French cognates to the French/English cognates used in Experiment 1 so that any differences in priming could be attributed to orthographic rather than to phonological factors. For the 60 Arabic/ French items, 22 pairs differed by one phoneme, and 4 pairs differed by two phonemes. Similarly, in the French/English set, 21 pairs differed by one phoneme, and 9 pairs differed by two phonemes. As in Experiment 1 , testing was conducted on a PowerBook 170 computer with an active matrix screen, using the Psychlab software package (Bub \& Gum, 1988).

Procedure. The same procedure was used as that in Experiment 1 .

\section{Results and Discussion}

The mean lexical decision latencies for correct responses and error rates in the various conditions of Experiments $3 \mathrm{~A}$ and $3 \mathrm{~B}$ are shown in Table 2. First, consider Experiment $3 \mathrm{~A}$, in which lexical decisions at test were performed in Arabic, the participants' first language. An ANOVA carried out on the RT data revealed a main effect of study-test relation, reflecting the robust repetition (92 $\mathrm{msec})$ priming, as well as a tendency for cross-modal ( $35 \mathrm{msec})$ and cognate $(31 \mathrm{msec})$ priming $\left[F(3,36)=6.51, M S_{\mathrm{e}}=3,570\right]$. A set of planned contrasts revealed significant repetition priming $[F(1,36)=2.85$, $\left.M S_{\mathrm{e}}=3,570\right]$, although the cross-modal and cognate priming scores only approached significance [both with $\left.F(1,36)<1.7, M S_{\mathrm{e}}=3,579, p>.10\right]$. Consistent with past studies, repetition priming was greater than cross-modal priming $\left[F(1,36)=2.85, M S_{\mathrm{e}}=3,579\right]$. The critical new 
Table 2

Lexical Decision Latencies (RTs, in Milliseconds), Error Rates, and Priming Values for Bilingual Arabic/French Speakers as a Function of the Study-Test Condition in Experiments $3 A$ and $3 B$

\begin{tabular}{|c|c|c|c|c|c|c|c|c|c|c|c|c|}
\hline \multirow[b]{3}{*}{ Priming } & \multicolumn{12}{|c|}{ Test Language } \\
\hline & \multicolumn{4}{|c|}{ Arabic } & \multicolumn{4}{|c|}{ French } & \multicolumn{4}{|c|}{ Combined } \\
\hline & RT & $\begin{array}{l}\text { RT Priming } \\
\text { Value }\end{array}$ & $\% \mathrm{E}$ & $\begin{array}{c}\% \text { E Priming } \\
\text { Value }\end{array}$ & RT & $\begin{array}{l}\text { RT Priming } \\
\text { Value }\end{array}$ & $\% \mathrm{E}$ & $\begin{array}{c}\% \text { E Priming } \\
\text { Value }\end{array}$ & RT & $\begin{array}{l}\text { RT Priming } \\
\text { Value }\end{array}$ & $\% \mathrm{E}$ & $\begin{array}{c}\% \text { E Priming } \\
\text { Value }\end{array}$ \\
\hline Repeat & 685 & 92 & 3.5 & 5.6 & 645 & 28 & 12.9 & 4.1 & 665 & 60 & 8.2 & 4.9 \\
\hline Cognate & 746 & 31 & 8.3 & 0.8 & 695 & -22 & 11.9 & 5.1 & 720 & 5 & 10.1 & 3.0 \\
\hline Cross-modal & 742 & 35 & 5.7 & 3.4 & 672 & 1 & 13.6 & 3.4 & 707 & 18 & 9.7 & 3.4 \\
\hline Baseline & 777 & & 9.1 & & 673 & & 17.0 & & 725 & & 13 & \\
\hline
\end{tabular}

finding is that priming for orthographically unrelated cognates was not significantly greater than cross-modal priming in these bilingual speakers $[F(1,36)<1]$; indeed, there was not even a trend in this direction. An overall analysis of the error scores revealed a main effect of studytest relation $\left[F(3,36)=3.29, M S_{\mathrm{e}}=35\right]$, reflecting the higher accuracy rate in the repeated condition, as compared with the other conditions.

In Experiment 3B, lexical decisions at test were performed in French, the participants' second language. An ANOVA carried out on the RT data revealed a main effect of study-test relation, reflecting the repetition $(28 \mathrm{msec})$ priming, as well as an apparent inhibitory effect for cognates $\left[-22 \mathrm{msec} ; F(3,36)=4.0, M S_{\mathrm{e}}=1,690\right]$. A set of planned contrasts revealed that repetition priming was marginally significant $\left[F(1,36)=1.94, M S_{\mathrm{e}}=1,690, p=\right.$ $.06]$, whereas the inhibitory cognate priming was not $\left[F(1,36)=1.5, M S_{\mathrm{e}}=1,690, p=.14\right]$. Repetition priming was also marginally greater than cross-modal priming $\left[F(1,36)=1.86, M S_{\mathrm{e}}=1,690, p=.07\right]$. An overall analysis of the error scores failed to reveal a main effect of study-test relation $[F(3,36)<1]$. However, the positive $5 \%$ cognate priming obtained for the errors was of a similar level of statistical significance $\left[F(1,36)=1.34, M S_{\mathrm{e}}=\right.$ $114, p=.19]$ as the inhibitory priming obtained for the RTs. Accordingly, there was a tendency for a speedaccuracy tradeoff in the cognate condition, with no evidence of priming when both dependent measures were considered together. Thus, in contrast with Experiment 1, there was no evidence of modality-specific cognate priming in Experiments 3A and 3B (in fact, in Experiment 3B, there was no cognate priming at all), suggesting that orthographic overlap is a necessary precondition in order to observe this effect.

What is less clear, however, is why substantially more priming was obtained when lexical decisions were performed in Arabic (Experiment $3 \mathrm{~A}$ ), as compared with French (Experiment 3B). This is, in fact, the opposite finding to that of Gollan et al. (1997), who obtained much less masked priming when the lexical decisions were performed in the first language. We should note that there were other differences, in addition to the size of the overall priming, including the fact that the lexical decisions for words took substantially longer in Arabic than in French (103 msec longer in the baseline condition) and that there were more errors in French $(17.0 \%$ vs. $9.1 \%$ in the baseline condition). It is possible that these differences are related to the contrasting priming results. It should also be emphasized that the Arabic/French bilinguals have been immersed in a French community for many years, so their first language may not always function as their dominant language (this contrasts with the French/English bilinguals in Experiment 1, for whom their native language was clearly dominant). Perhaps the smaller priming for the French targets reflects the fact that French is functionally the dominant language for many of these participants. Whatever the reason, we want to emphasize that no modality-specific cognate priming was obtained in either Experiment 3A or Experiment 3B, suggesting that this result is quite robust and extends to conditions in which the speakers' first or second language is the test language.

\section{GENERAL DISCUSSION}

Three main results are reported in the present investigation: (1) Modality-specific cognate priming was obtained for orthographically similar French/English cognates in bilingual speakers, (2) no cognate priming was obtained for the same French/English items in monolingual speakers, and (3) no modality-specific cognate priming was obtained for orthographically unrelated Arabic/French cognates in bilingual speakers. This combination of results suggests that orthographic overlap between items is necessary but not sufficient to obtain modality-specific cognate priming. That is, there appears to be some interaction between orthographic representations, on the one hand, and semantic and phonological codes, on the other, that supports these effects.

On the one hand, the modality-specific French/English cognate priming lends support to the conclusion that words in different languages are processed within the same orthographic system (e.g., Grainger \& Dijkstra, 1992). Indeed, these results seem to suggest that cognate relations are explicitly represented within the orthographic system. On the other hand, the failure to obtain modalityspecific priming for the Arabic/French cognates raises a number of issues that are difficult to resolve at the present time. One possible interpretation of this finding is that separate orthographic systems are involved in processing the French and the Arabic words, eliminating any basis for mapping these words together. On this ac- 
count, then, language-independent orthographic systems are restricted to conditions in which the languages in question share similar orthographies. Alternatively, the Arabic/ French words might be processed within a common orthographic system, but for some reason, cognate relations are not explicitly coded for these items.

Unfortunately, there is not much evidence that speaks directly to these two hypotheses. Gollan et al. (1997) reported masked priming between orthographically unrelated Hebrew/English cognates, consistent with the hypothesis that these items are mapped together within a common system. However, the authors also reported masked priming between Hebrew/English translation equivalents, suggesting that this priming was mediated, at least in part, by conceptual representations outside the orthographic system. Thus, the relevance of these results to the present issue is unclear. Perhaps more relevant is the robust and modality-specific priming obtained between the orthographically unrelated Kanji/Hiragana scripts of Japanese (Bowers \& Michita, 1998). On the basis of these results, the authors argued that Hiragana and Kanji words map onto common lexical-orthographic representations within a common system, despite their unrelated orthographies. If indeed this is the case, it seems plausible to assume that Arabic/French words are also processed within a common orthographic system. On this view, then, Arabic/ French cognates are not explicitly linked together within a common orthographic system, unlike upper- and lowercase English words and Kanji/Hiragana Japanese words.

Whatever the proper interpretation of the Arabic/ French findings, the question still remains as to why a different pattern of results was obtained for the Arabic/ French and the French/English cognates. Again, we cannot make any strong conclusions but will offer the following speculation. Perhaps the orthographic system fails to explicitly link the French/English as well as the Arabic/French cognates, and the modality-specific French/ English cognate priming reflects specific processes associated with these items. That is, it is possible that the French/English participants explicitly translated the English words into French within the orthographic system during the study phase of the experiment, effectively generating the visual structure of the alternative test word through imagery. If this occurred, the orthographic codes for both English and French words would be strengthened-leading to the observed priming results.

It should be noted that this form of translation does occur in some circumstances. For example, Kirsner et al. (1984) observed priming between noncognate English/ French translation-equivalent words (e.g., dog/chien) when participants were asked to translate words at study in such a way that the orthographic knowledge of the nonstudied member of the translation pair was accessed; specifically, the participants reported the initial letter and the number of letters in the translation. When these same French/English words were studied semantically, by making animate/inanimate decisions, no cross-language priming was obtained. In addition, McDermott and Roediger (1994) observed priming in a word-fragment com- pletion task when participants imagined the spelling of a word, given its picture at study, whereas no priming was obtained when participants were not instructed to imagine its spelling. Thus, as long as the French/English participants spontaneously activated the French words when reading English at study, the modality-specific priming results should be expected.

In order to accommodate the Arabic/French results, we would suggest that spontaneous translation between cognates occurs only when items are orthographically related. In line with this argument, it should be noted that the process of reading a word in one language results in the partial activation of form-related words in a second language in bilingual speakers (van Heuven et al., 1998). Thus, it should be expected that both members of a French/English cognate pair should be partially activated following the reading of either member, owing to their form overlap. This coactivation, in combination with phonological and semantic overlap between these cognates, might result in the full activation of both items within the orthographic system, resulting in modalityspecific priming. By contrast, the lack of form overlap between French/Arabic cognates would have eliminated any coactivation from form overlap, which, in turn, may have prevented the spontaneous translation between items-eliminating the modality-specific priming. But again, we acknowledge that this interpretation is speculative, and future work is necessary before more definitive conclusions can be offered.

In sum, the present set of studies shows that cognate priming is largely mediated by modality-specific representations and, further, that modality-specific priming is restricted to orthographically related items. Although the implications of these findings are not entirely clear with regards to how (or whether) cognate relations are coded within orthography, the results provide important constraints that should be considered in future theorizing on this issue.

\section{REFERENCES}

BAUDOT, J. (1992). Fréquence d'utilisation des mots en français écrit contemporain. Montreal: Presses Universitaires de Montréal.

Biederman, I., \& Gerhardstein, P. C. (1993). Recognizing depthrotated objects: Evidence for 3-D viewpoint invariance. Journal of Experimental Psychology: Learning, Memory, \& Cognition, 19 , 1162-1182.

BLAXTON, T. A. (1989). Investigating dissociations among memory measures: Support for a transfer-appropriate processing framework. Journal of Experimental Psychology: Learning, Memory, \& Cognition, 15, 657-668.

BowERS, J. S. (1996). Different perceptual codes support word and pseudoword priming: Was Morton right all along? Journal of Experimental Psychology: Learning, Memory, \& Cognition, 22, 1336-1353.

Bowers, J. S. (1999). Priming is not all bias: Commentary on Ratcliff and McKoon (1997). Psychological Review, 106, 582-596.

BowERS, J. S. (2000). In defense of abstractionist theories of repetition priming and word identification. Psychonomic Bulletin \& Review, 7 , 83-99.

Bowers, J. S., Damian, M. F., \& Havelka, J. (1999). Can distributed orthographic knowledge support word-specific long-term priming? Apparently so. Manuscript submitted for publication.

BOWERS, J .S., \& MICHITA, Y. (1998). An investigation into the structure 
and acquisition of orthographic knowledge: Evidence from crossscript Kanji-Hiragana priming. Psychonomic Bulletin \& Review, 5 , 259-264.

Bowers, J. S., Vigliocco, G., \& HaAN, R. (1998). Orthographic, phonological, and articulatory contributions to masked letter and word priming. Journal of Experimental Psychology: Human Perception \& Performance, 24, 1705-1719.

Brown, H. L., Sharma, N. K., \& Kirsner, K. (1984). The role of script and phonology in lexical representation. Quarterly Journal of Experimental Psychology, 36A, 491-505.

BuB, D., \& GuM, T. (1988), Psychlab software. Montreal: McGill University.

Caramazza, A., \& Brones, I. (1979). Lexical access in bilinguals. Bulletin of the Psychonomic Society, 13, 212-214.

Church, B. A., \& SCHACTER, D. L. (1994). Perceptual specificity of auditory priming: Implicit memory for voice intonation and fundamental frequency. Journal of Experimental Psychology: Learning. Memory, \& Cognition, 20, 521-533.

Coltheart, M. (1981). Disorders of reading and their implications for models of normal reading. Visible Language, 3, 245-286.

Cristoffanini, P., Kirsner, K., \& Milech, D. (1986). Bilingual lexical representation: The status of Spanish-English cognates. Quarterly Journal of Experimental Psychology, 38A, 367-393.

De Groot, A. M. B., \& NASS, G. L. J. (1991). Lexical representation of cognates and noncognates in compound bilinguals. Journal of Memory \& Language, 30, 90-123.

Dujkstra, T., Grainger, J., \& van Heuven, W. J. B. (1999). Recognition of cognates and interlingual homographs: The neglected role of phonology. Journal of Memory \& Language, 41, 496-518.

Dijkstra, T., \& van Heuven, W. J. B. (1998). The BIA-model and bilingual word recognition. In J. Grainger \& A. Jacobs (Eds.), Localist connectionist approaches to human cognition (pp. 189-225). Hillsdale NJ: Erlbaum.

Feldman, L. B., \& Moskovljevic, J. ( 1987). Repetition priming is not purely episodic in origin. Journal of Experimental Psychology: Learning, Memory, \& Cognition, 13, 573-581

Forster, K. I., \& DaVIS, C. (1984). Repetition priming and frequency attenuation in lexical access. Journal of Experimental Psychology: Learning, Memory, \& Cognition, 10, 680-698.

Garcia-Albea, J. E., Sanchez-Casas, R. M., Bradley, D. C., \& Forster, K. I. (1985, November). Cross-language priming effects in bilingual word recognition. Paper presented at the meeting of the Fifth Australian Language Conference, Melbourne

GolDingER, S. D. (1996). Words and voices: Episodic traces in spoken word identification and recognition memory. Journal of Experimental Psychology: Learning, Memory, \& Cognition, 22, 1166-1183.

Gollan, T. H., Forster, K. I., \& Frost, R. (1997). Translation priming with different scripts: Masked priming with cognates and noncognates in Hebrew-English bilinguals. Journal of Experimental Psychology: Learning, Memory, \& Cognition, 23, 1122-1139.

GraingER, J., \& DiJkstra, T. (1992). On the representation and use of language information in bilinguals. In R. J. Harris (Ed.), Cognitive processing in bilinguals (pp. 207-252). Amsterdam: Elsevier.

Henderson, L., Wallis, J., \& KNight, D. (1984). Morphemic structure and lexical access. In H. Bouma \& D. G. Bouhuis (Eds.), Attention and performance $X$ : Control of language processes (pp. 211 226). Hillsdale, NJ: Erlbaum.

JACOBY, L. L., \& DALlAS, M. (1981). On the relationship between autobiographical memory and perceptual learning. Journal of Experimental Psychology: General, 110, 306-340.

JoORdENS, S., \& BECKER, S. (1997). The long and short of semantic priming effects in lexical decision. Journal of Experimental Psychology: Learning, Memory, \& Cognition, 23, 1083-1105.

KirSner, K., Smith, M. C., Lockhart, R. S., King, M. L., \& Jain, M (1984). The bilingual lexicon: Language-specific units in an integrated network. Journal of Verbal Learning \& Verbal Behavior, 23, 519-539.

Kroll, J. F., \& DE Groot, A. M. B. (1997). Lexical and conceptual memory in the bilingual: Mapping form to meaning in two languages.
In A. M. B. de Groot \& J. F. Kroll (Eds.), Tutorials in bilingualism: Psycholinguistic perspectives (pp. 169-199). Mahwah, NJ: Erlbaum. KUČERA, J., \& FRANCES, W. N. (1967). Computational analysis of present day American English. Providence, RI: Brown University Press. Marsolek, C. J., Kosslyn, S. M., \& SQuire, L. R. (1992). Formspecific visual priming in the right cerebral hemisphere. Journal of Experimental Psychology: Learning, Memory, \& Cognition, 18, 492-508.

MCDermotT, K. B., \& RoEDiger, H. L., III (1994). Effects of imagery on perceptual implicit memory tests. Journal of Experimental Psychology: Learning, Memory, \& Cognition, 20, 1379-1390.

Monsel., S., MatThews, G. H., \& Miller, D. C. (1992). Repetition of lexicalization across languages: A further test of locus of priming. Quarterly Journal of Experimental Psychology, 44A, 763-783.

MORTON, J. (1979). Facilitation in word recognition: Experiments causing change in the logogen model. In P. A. Kolers, M. E. Wrolstad, \& H. Bouma, Processing models of visible language (pp. 259-268). New York: Plenum.

NAPPS, S. E., \& Fowler, C. A. (1987). Formal relationships among words and the organization of the mental lexicon. Journal of Psycholinguistic Research, 16, 257-272.

NeISSER, U. (1954). An experimental distinction between perceptual processes and verbal response. Journal of Experimental Psychology, 47, 399-402.

Rajaram, S., \& Roediger, H. L., III (1993). Direct comparison of four implicit memory tests. Journal of Experimental Psychology: Learning, Memory, \& Cognition, 19, 765-776.

RAPP, B. C. (1992). The nature of sublexical orthographic organization: The bigram trough hypothesis examined. Journal of Memory \& Language, 31, 33-53.

ROEDIGER, H. L., III, \& MCDERMOTT, K. B. (1993). Implicit memory in normal human subjects. In F. Boller \& J. Grafman (Eds.), Handbook of neuropsychology (Vol. 8, pp. 63-131). New York: Elsevier.

RUECKL, J. G. (1990). Similarity effects in word and pseudoword repetition priming. Journal of Experimental Psychology: Learning, Memory, \& Cognition, 16, 374-391.

RuECKL, J. G., \& MATHEW, S. (1999). Implicit memory for phonological processes in visual stem completion. Memory \& Cognition, 27, $1-11$.

RUECKL, J. G., \& OLDS, E. M. (1993). When pseudowords acquire meaning: Effect of semantic associations on pseudoword repetition priming. Journal of Experimental Psychology: Learning, Memory, \& Cognition, 19, 515-527.

Sanchez-Casas, R. M., Davis, C. W., \& Garcia-Albea, J. E. (1992). Bilingual lexical processing: Exploring the cognate/noncognate distinction. European Journal of Cognitive Psychology, 4, 293-310.

Scarborough, D. L., Gerard, L., \& Cortese, C. (1984). Independence of lexical access in bilingual word recognition. Journal of Verbal Learning \& Verbal Behavior, 23, 84-99.

Sloman, S. A., Hayman, C. A. G., Ohta, N., Law, J., \& Tulving, E. (1988). Forgetting in primed fragment completion. Journal of Experimental Psychology: Learning, Memory, \& Cognition, 14, 223-239. Sмiтн, M. S. (1997). How do bilinguals access lexical information? In A. M. B. de Groot \& J. F. Kroll (Eds.), Tutorials in bilingualism: Psycholinguistic perspectives (pp. 145-168). Mahwah, NJ: Erlbaum.

SRINIVAS, K. (1995). Representation of rotated objects in explicit and implicit memory. Journal of Experimental Psychology: Learning. Memory, \& Cognition, 21, 1019-1036.

TENPENNY, P. L. (1995). Abstractionist versus episodic theories of repetition priming and word identification. Psychonomic Bulletin \& Review, 2, 339-363.

van Heuven, W. J. B., Dijkstra, T., \& Grainger, J. (1998). Orthographic neighborhood effects in bilingual word recognition. Journal of Memory \& Language, 39, 458-483.

ZIEMER, H. E., \& BOWERS, J. S. (1999). Phonological and orthographic contributions to long-term priming in the lexical decision task. Manuscript submitted for publication.

(Manuscript received May 27, 1997; revision accepted for publication January 21,2000 .) 